\title{
Flexural Behaviour of Recycled Demolition Waste Reinforced Concrete Beams
}

\author{
Husham Mohammed Rashid ${ }^{1}$, Hasan Jasim Mohammed ${ }^{2}$ \\ \{hushammoh99@st.tu.edu.iq ${ }^{1}$,dr.hassanjassim@tu.edu.iq $\left.{ }^{2}\right\}$ \\ Department of Civil Engineering, Faculty of Engineering, \\ Tikrit University, P.O. Box (42) Tikrit, Iraq ${ }^{1,2}$
}

\begin{abstract}
The experimental study investigates the effect of using recycled demolition aggregate (RDA) on the flexural behaviour of reinforced concrete beams. The beams were $1400 \mathrm{~mm}$ long, $150 \mathrm{~mm}$ wide and $200 \mathrm{~mm}$ deep, with the same longitudinal and shear reinforcement. The replacement ratios of recycled demolition aggregate are $0 \%, 25$ $\%, 50 \%, 75 \%$, and $100 \%$ of the coarse aggregate weight. The results presented that the deflections of the beams were reduced by up to $15 \%$ and $43 \%$ of $75 \%$ RDA and $100 \%$ RDA, respectively when compared to the control beam. Furthermore, at $100 \%$ RDA, ductility, stiffness, and toughness were reduced by approximately $24 \%, 10 \%$, and $34 \%$, respectively. At the same stage of loading, RDA beams cracked faster than normal aggregate beams.
\end{abstract}

Keywords: Recycled demolition waste, Reinforced concrete, Flexural, Beams, Coarse aggregate.

\section{Introduction}

It is important to understand the effect of recycled demolition aggregate (RDA) on the behaviour of reinforced concrete (RC) beams under flexural strength to assess the material's potential use in structural elements. Numerous studies have been conducted to evaluate the use of RDA in structural elements, beams, slabs, columns, and so on. This topic is also relevant given the anticipated increase in perceptible coarse aggregate consumption [1]. The mechanical properties of natural coarse aggregate replaced with recycled concrete aggregate (RCA) or recycled clay brick aggregate are being investigated. There are five replacement rate ratios considered: $0 \%, 25 \%, 50 \%, 75 \%$, and $100 \%$. The reduction in compressive strength is about $13 \%$ for replaced with $100 \%$ replacing [2]. Properties of concretes made with higher strengths than their parallel made with normal concrete [3]. Several previous studies have demonstrated that using recycled demolition aggregates in concrete reduces workability, strength, and durability issues [4], [5], [6], [7], [8], [9]. In most cases, RCA has two interfacial transition zones (old and new). It is the weakest part of the concrete. As a result, failure is often the result. Furthermore, Fig 1 showed the failure shapes of natural aggregate concrete, recycled aggregate concrete upon compressive strength, and split tensile strength tests [10]. 

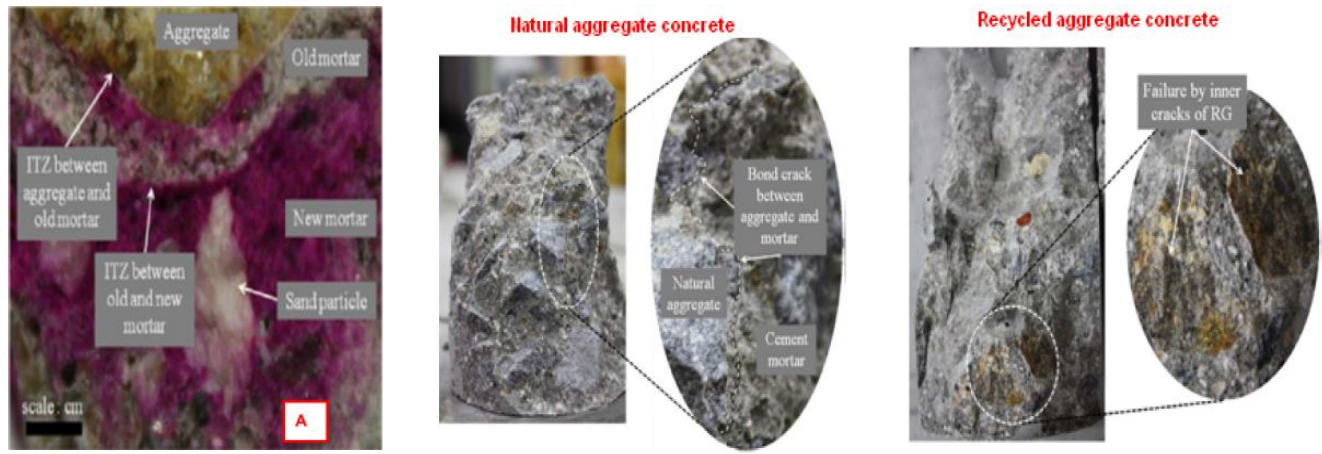

Fig. 1. The failure shape for NA and RCA [14].

The research aim is to investigate the flexural behaviour of RC beams with different recycled demolition aggregate ratios. The replacement ratios of recycled demolition aggregate are $0 \%$, $25 \%, 50 \%, 75 \%$, and $100 \%$ of the coarse aggregate weight. The effect study is concerned with the flexural strength of RC beams, as well as the crack pattern and failure modes. The ductility, stiffness, and toughness of these RC beams were then evaluated.

\section{Experimental Program}

This study looks at the flexural behaviour of reinforced concrete beams made with various percentages of recycled demolition aggregate.

\subsection{Sample Design of RC Beams}

Five RC beams were created (one normal aggregate (NA) and four RDA). Beams have a variety of RDA ratios $(0 \%, 25 \%, 50 \%, 75 \%$ and $100 \%)$ of the coarse aggregate weight. All the beams were designed to fail in flexural, with shear reinforcements added to prevent shear failure and meet the requirements of ACI 318-19. As shown in Fig 2, the dimensions of all RC beams are $1400 \mathrm{~mm}$ long, $150 \mathrm{~mm}$ width, and $200 \mathrm{~mm}$ depth.

\subsection{Materials}

Ordinary Portland cement type (I) with a compressive strength of $41 \mathrm{MPa}$ at age 28-day was used. The cement passed the ASTM C150 / C150M-19a test. Natural river sand with a water absorption rate of about $1 \%$ and with an oven-dry relative density of 2.66 was used. Moreover, it has a moisture content of $2.8 \%$, fineness modulus is 2.68 of sand used, and all results meet ASTM C778-17 specifications. Natural coarse aggregate with a maximum size of $12.5 \mathrm{~mm}$, an absorption of $0.45 \%$, an oven-dry relative density of 2.6 , and a moisture content of coarse aggregate of $1 \%$ was used, and all outcomes conformed to the ASTM C33 / C33M18 specifications. The recycled demolition aggregate (RDA) with an angular shape (12.5 mm maximum size), absorption of $2.56 \%$, and oven-dry density are 2.52 was used RDA composition as presented in Fig. 3 includes the RDA component percentages of $78.7 \%, 11.9$ 
$\%, 8.9 \%$, and $0.8 \%$ of recycled concrete aggregate, masonry, tiles, and gypsum, respectively. It passed the ASTM C33 / C33M-18 tests. The plasticizer used is a high-performance, hydrophobic material that meets ASTM C-494-Type B requirements. A quantity of plasticizer, $1.78 \%$ of the weight of the cement was applied. The longitudinal reinforcement in the tension zone is $2 \varnothing 8 \mathrm{~mm}$ and in the compression, the zone is $2 \varnothing 6 \mathrm{~mm}$, also the shear steel reinforcement is $\varnothing 6 \mathrm{~mm} @ 80 \mathrm{~mm}$ for all beams were used. It was passed the ASTM A615/A615M-15a tests. The mixes included replacing $0 \%, 25 \%, 50 \%, 75 \%$, and $100 \%$ of the coarse aggregate weight with recycled RDA. The normal concrete was mixed in the same ratio (1:1.5:2.0) specified by ACI code requirements (ACI 211). While the RDA concrete was replacing the ratio of the coarse aggregate weight by RDA.
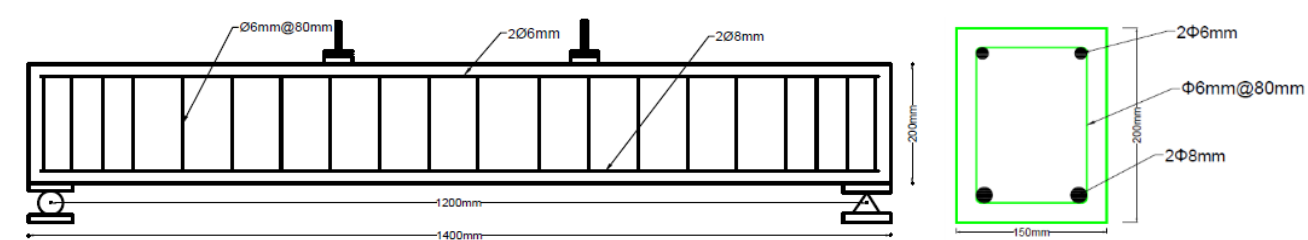

Fig. 2. Details of RC beams used in the experimental program.
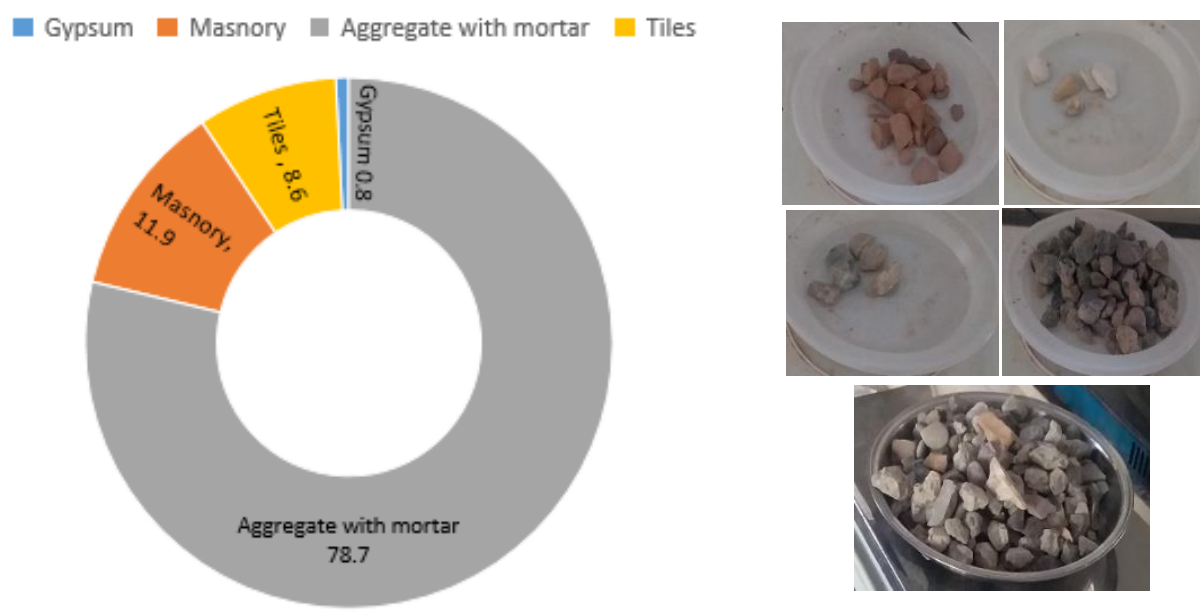

Fig. 3. Recycled demolition aggregate composition.

\subsection{Test Setup and Instrumentation}

Under a static load, all RC beams were tested to failure. In the mid-span, one LVDT that measures mid-span deflection was installed. A 200-ton load cell measures the load on beams from the universal machine. The data logger collects information from the LVDT and the load cell. The load applied to the beam was gradually increased at a rate of $2 \mathrm{~mm} / \mathrm{min}$. A white colour paint directly on each beam marked the propagation of cracks. A four-point loading test 
was performed on the simply supported RC beams, which were supported using steel rods and subjected to two loads. The maximum load, deflection, and crack pattern of the first major crack were recorded.

\section{Experimental Results and Discussion}

\subsection{Flexural Behaviour of RC Beams}

Table 1 displays the results of the RC beam tests. The load-deflection curves of all tested RC beams are shown in Fig 4, which describes the behaviour of RDA/NA RC beams from the beginning of loading until complete failure. The flexural strength of RC beams with NA and RC beams with RDA exhibit nearly identical elastic behaviour in the first stage of loading. In addition, the occurrence of a behaviour changes load-deflection curve in the second stage of loading revealed that the load-carrying capacities of the RDA concrete beams are slightly lower than of the NA concrete beams. The test results show that the ultimate flexural strength of $\mathrm{RC}$ beams containing $25 \%$ and $50 \%$ recycled demolition aggregate is not reduced when compared to NA beams. While the replacement ratio was increased from $75 \%$ to $100 \%$, there was a $15 \%$ and $43 \%$ decrease in ultimate flexural strength, respectively. This reduction in RDA beams is because the weaker aggregate has a greater effect on the strength of the concrete, after a reduction in the ultimate strength of the $\mathrm{RC}$ beam.

Table 1. Results of Tested RC beams.

\begin{tabular}{|c|c|c|c|c|c|c|}
\hline \multirow{2}{*}{ Group. No. } & \multirow{2}{*}{$\begin{array}{l}\text { Beam } \\
\text { Designation }\end{array}$} & \multirow{2}{*}{$\mathrm{Py}(\mathrm{kN})$} & \multirow{2}{*}{$\mathrm{Pu}(\mathrm{kN})$} & \multicolumn{2}{|c|}{ Deflection (mm) } & \multirow{2}{*}{$\begin{array}{l}\mathrm{Pu} \\
\text { Change \% }\end{array}$} \\
\hline & & & & $\delta y$ & $\delta \mathrm{u}$ & \\
\hline Beam with NA & BR-0\% & 46.5 & 69.62 & 4.8 & 30.92 & --- \\
\hline \multirow{4}{*}{ Beams with RDA } & BR-25\% & 49.83 & 69.95 & 5.66 & 31.4 & +0.47 \\
\hline & BR-50\% & 46.7 & 68.55 & 5.20 & 26.86 & -1.56 \\
\hline & BR-75\% & 40.9 & 60.71 & 5.95 & 29.59 & -14.67 \\
\hline & BR-100\% & 31.23 & 48.61 & 4.35 & 21.19 & -43.22 \\
\hline
\end{tabular}

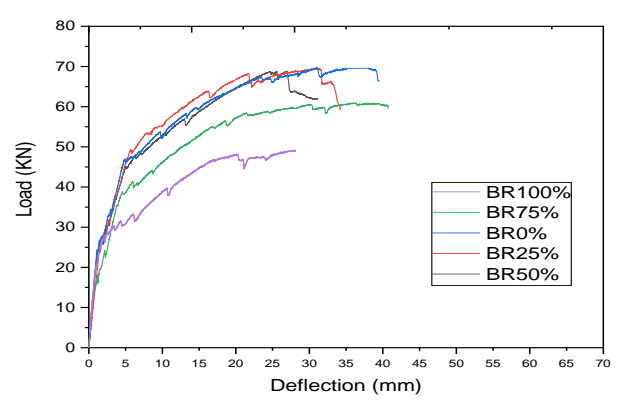

Fig. 4. Load-deflection curves of tested RC beams. 


\subsection{Crack Pattern and Failure Modes for Flexural RC Beams}

Fig 5 shows the propagation of RC beams with the main wide cracks located in the centre of the beam's mid-span. The width of the cracks gradually decreases as they spread towards the top chord until they reach the top layer. Before the appearance of cracking, the linear elastic behaviour of the RC beams was observed until the cracking load. Curve fractures occur because of the beginning of cracking in the beams as loading increases. The number of cracks and crack width is greater in RDA beams than in NA beams. In addition, as the percentage of RDA in RC beams increased, so did the number and width of cracks.

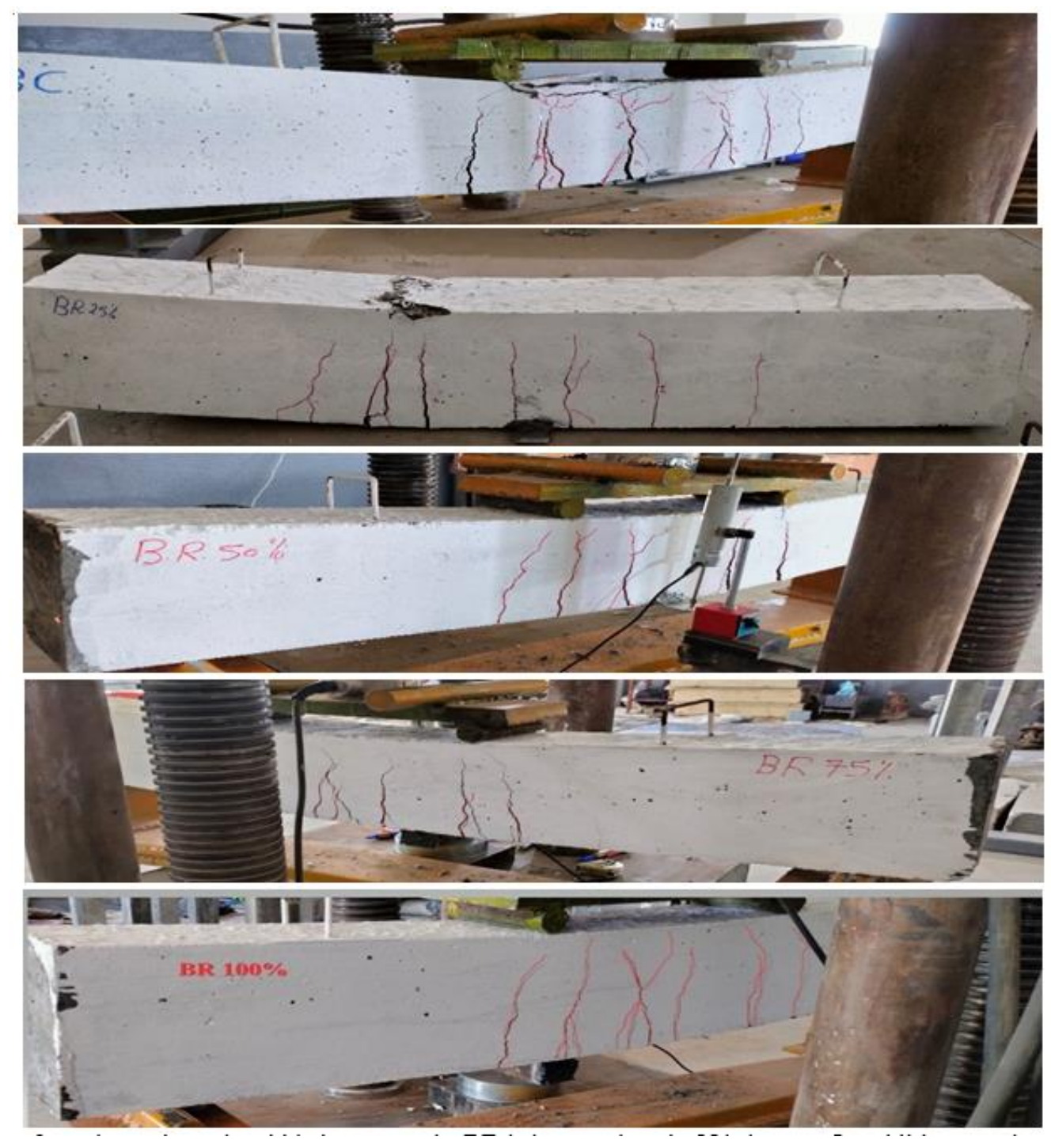

Fig. 5. The crack pattern of all tested RC beams. 


\subsection{Ductility Behaviour}

Depending on the type and proportion of the replaced aggregate, substituting the RDA may increase or decrease the ductility index. According to Fig.6, the ductility values for RDA beams decreased because they had less deflection at the failure loading and more deflection value at the elastic limit. All ductility index values decreased because of the decreased ultimate deflection of the RDA beams. Furthermore, the test results show a reduction in ductility index of $(15,20,23$, and 24$) \%$ as RDA replacement was increased from $(25,50,75$, and 100) $\%$, respectively. The decrease in ductility is caused by the tensile strength of RDA concrete, which gradually decreases as the proportion of replaced aggregates increases.

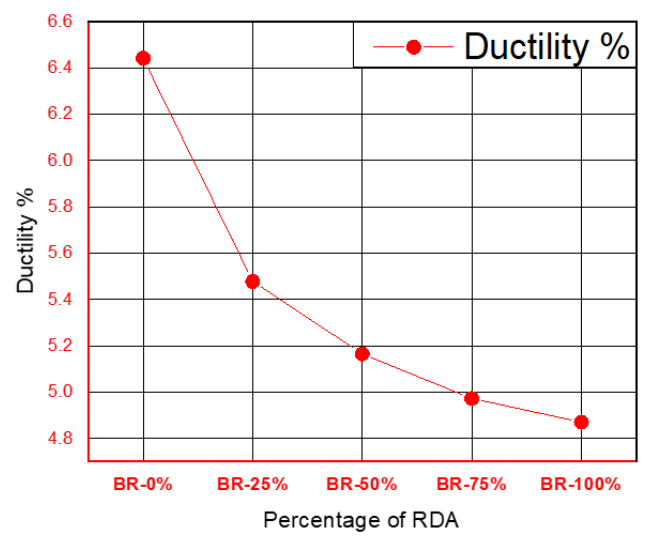

Fig.6. Ductility of RC beams.

\subsection{Stiffness Behaviour}

Fig 7 illustrates the stiffness values of RC beams. The value of stiffness beams with RDA is found to be lower than the value of the $\mathrm{NC}$ beam. The stiffness results show a slight reduction in stiffness of $(0.55,1.89,6.8$, and 10.45$) \%$ as the RDA replacement was increased from $(25$, 50,75 , and 100) $\%$, respectively. Decreasing in stiffness due to the lower strength of concrete with RDA, as well as fractures in the load-deflection curve, the higher the reason for this is that the strength of RDA is weak and the presence of two interfacial transition zones compared to normal aggregates.

\subsection{Toughness Behaviour}

Fig 8 shows that the flexural toughness values for (BR25\%, BR50\%, BR 75\%, and BR100\%) beams decreased because they had less deflection at the failure loading and more deflection value at the elastic limit. All flexural toughness values decreased due to a decrease in the loaddeflection curve of the RDA beams. Furthermore, the test results show a decrease in flexural toughness of $(0.4,11.9,27.8$, and 33.9$) \%$ as RDA replacement was increased from $(25,50$, 75 , and 100$) \%$, respectively. 


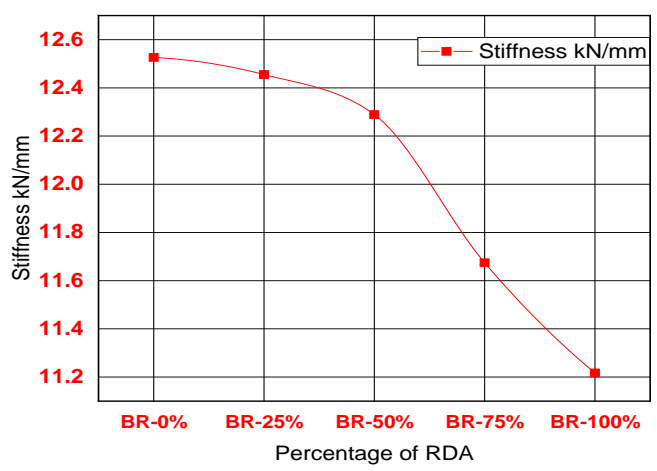

Fig.7. Stiffness of RC beams.

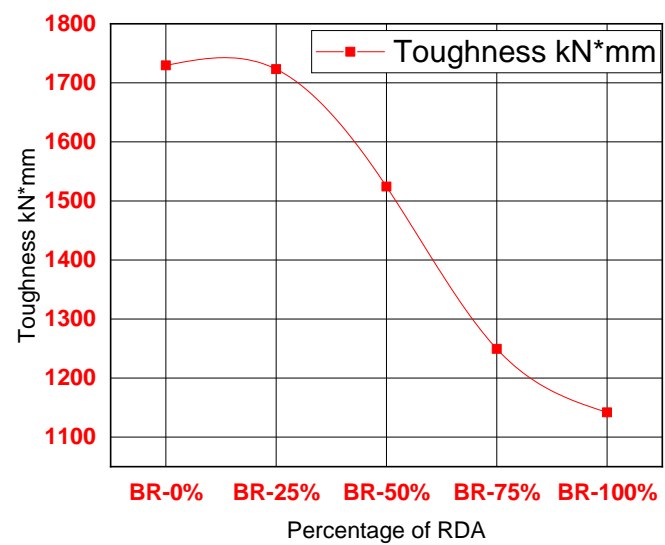

Fig.8. Toughness of RC beams.

\section{Conclusions}

The experimental study looks at how using recycled demolition aggregate (RDA) affects the flexural behaviour of reinforced concrete beams. The beams were $1400 \mathrm{~mm}$ long, $150 \mathrm{~mm}$ wide, and $200 \mathrm{~mm}$ deep, and they were reinforced longitudinally and shear. The replacement ratios of RDA are $0 \%, 25 \%, 50 \%, 75 \%$, and $100 \%$ of the coarse aggregate weight.

1. For high ratio of RDA replacement, the flexural strength of the RC beam decreased. While the flexural strength low percentage of RDA replacement decreased slightly.

2. At the ultimate load, RC-RDA beams showed less deflection than the control beam.

3. The ductility values of RDA beams varied depending on the maximum and elastic limit deflection values. The reduction in ductility of $(15,20,23$, and 24$) \%$ as RDA replacement was increased from $(25,50,75$, and 100$) \%$, respectively. 
4. RDA beams stiffness was lower than normal beam stiffness about $10.48 \%$ at $100 \%$ RDA replacement.

5. At $100 \%$ RDA replacement, RDA beam toughness was about $33.9 \%$ lower than normal beam stiffness.

\section{Acknowledgments}

Tikrit University has provided support for this study. The authors would like to express their appreciation to the university specialists who assisted them with this study. This study is not applicable for funding.

\section{References}

[1] Bai G., Zhu C., Liu C., and Liu B., An evaluation of the recycled aggregate characteristics and the recycled aggregate concrete mechanical properties. Construction and Building Materials. 2020; 240: 117978 .

[2] Chaocan Zheng, Cong Lou, Geng Du, Xiaozhen Li, Zhiwu Liu and Liqin Li. Mechanical properties of recycled concrete with demolished waste concrete aggregate and clay brick aggregate. Results in Physics. 2018; 9: 1317-1322.

[3] Arezoumandi M, Drury J, Volz JS, and Khayat KH. Effect of recycled concrete aggregate replacement level on shear strength of reinforced concrete beams. ACI Mater. J. 2015; 112(4).

[4] Shirani Bidabadi M., Akbari M., and Panahi O.,. Optimum mix design of recycled concrete based on the fresh and hardened properties of concrete. Journal of Building Engineering. 2020; 32: 101483.

[5] Peng L., Zhao Y., and Zhang H.,. Flexural behaviour and durability properties of recycled aggregate concrete (RAC) beams subjected to long-term loading and chloride attacks. Construction and Building Materials. 2021; 277:122277.

[6] Zhu C., Liu C., Bai G., and Fan J.,. Study on long-term performance and flexural stiffness of recycled aggregate concrete beams. Construction and Building Materials. 2020; 262: 120503.

[7] Sadowska-Buraczewska B., Barnat-Hunek D., and Szafraniec M.,. Influence of Recycled HighPerformance Aggregate on Deformation and Load-Carrying Capacity of Reinforced Concrete Beams. Materials. 2020; 13: 186.

[8] Rahal K., and Elsayed K.,. Shear strength of $50 \mathrm{MPa}$ longitudinally reinforced concrete beams made with coarse aggregates from low strength recycled waste concrete. Construction and Building Materials. 2021; 286: 122835.

[9] Arezoumandi M, Smith A, Jeffery AS and Khayat H. An experimental study on flexural strength of reinforced concrete beams with 100\% recycled concrete aggregate. Engineering Structures. 2015; 88: 154-162.

[10] Lee GC and Choi HB. Study on interfacial transition zone properties of recycled aggregate by micro-hardness test. Construction and Building Materials. 2013; 40: 455-460. 